\title{
RODOVIAS NA AMAZÔNIA E AS MUDANÇAS RECENTES NA CIRCULAÇÃO REGIONAL
}

\author{
Highways in the Amazon and recent changes in regional traffic
}

\section{Carreteras en la Amazonía y cambios recientes en el tráfico regional}

\author{
Thiago Oliveira Neto \\ Doutorando em Geografia Humana pela USP \\ thiagoton91@live.com
}

Artigo enviado para publicação em 23/01/2020 e aceito em 04/07/2020

DOI: $10.12957 /$ tamoios.2020.47935

\begin{abstract}
Resumo
As rodovias e os projetos governamentais na Amazônia ocasionaram diversas transformações territoriais com o estabelecimento de fluxos entre essa região e as demais do país. Novas transformações estão em andamento com o processo de conclusão da rodovia BR-163, no estado do Pará, e com a retomada da trafegabilidade sazonal na BR319, no estado do Amazonas. Nesse contexto, o texto aborda as transformações nos dois eixos rodoviários e a expansão dos investimentos da logística corporativa em duas frações territoriais distintas da Amazônia brasileira.
\end{abstract}

Palavras-chave: logística, rodovias, Amazônia.

\begin{abstract}
The highways and the government projects in the Amazon caused several territorial transformations with the establishment of flows between this region and the rest of the country. New transformations are underway in this the completion of the BR-163 highway in the state of Pará and the resumption of seasonal traffic on the BR-319 in the state of Amazonas. In this context, text addresses the transformations in the two highway axes and the expansion of corporate logistics investments in two distinct territorial fractions of the Brazilian Amazon.
\end{abstract}

Keywords: logistics, highways, Amazon.

\section{Resumen}

Las carreteras y los proyectos gubernamentales en la Amazonía causaron varias transformaciones territoriales con el establecimiento de flujos entre esta región y el resto del país. Se están realizando nuevas transformaciones con el proceso de completar la carretera BR-163 en el estado de Pará y con la reanudación del tráfico estacional en la BR-319 en el estado de Amazonas. En este contexto, el texto aborda las transformaciones en los dos ejes de carreteras y la expansión de las inversiones en logística corporativa en dos fracciones territoriales distintas de la Amazonía brasileña.

Palabras clave: logística, carreteras, Amazonía. 


\section{Introdução}

Os transportes com fluxos fluviais, rodoviários, ferroviários e aéreos constituem um conjunto de redes que também fazem parte das dinâmicas urbanas e da própria rede urbana amazônica. De forma particular, os deslocamentos rodoviários tiveram alterações na Amazônia no momento da construção das rodovias e da pavimentação destas, sendo que nesse último, nota-se a formação de outras redes e a potencialização de determinados processos relacionados aos fluxos, com atuação empresarial na montagem de infraestruturas e a consolidação de viagens de caminhões e de ônibus.

Os autores Almeida e Ribeiro (1989), Corrêa (1987) e Ribeiro (1998), analisaram a circulação e a rede urbana na Amazônia após a construção das grandes rodovias na região, como também, estudaram as expansões das atividades econômicas e de fluxos entre essa região com as demais do país. Mas, ao longo de mais de 20 anos e, após a publicação desses trabalhos e o esforço do Estado em concluir os grandes eixos construídos, e somando-se com a atuação de grandes corporações que propiciaram a alteração nos fluxos com um novo desenho na circulação dentro dessa região. Nesse sentido, o texto busca explorar essas alterações nos eixos da rodovia BR-163 e BR-319.

Optamos em apontar apenas os eixos da rodovia BR-163 no estado do Pará e da BR-319 no estado do Amazonas, pois, são grandes eixos viários com mais $800 \mathrm{~km}$ de extensão que estão passando por transformações recentes com a formação de redes de circulação de pessoas e de cargas, algo que já aconteceu e está consolidado ao longo da BR-174 no trecho Manaus-Pacaraima, asfaltado em sua totalidade em 1998. Desse mesmo modo, a, BR-364 entre as cidades de Cuiabá e Porto Velho em 1984 e de Porto Velho para Rio Branco em 1987, como também, na Belém-Brasília concluído em 1974. Além disso, tecemos reflexões sobre esses dois eixos (BR-163 e BR-319) de circulação de forma diferenciada, pois apesar de estarem situados na Amazônia, cada eixo tem um contexto histórico particular e condições atuais completamente diferente, além da espacialidade da circulação ser distintas.

Para abordar essas transformações, estruturamos o texto em 3 partes: primeiramente apontando as transformações na circulação interna na Amazônia com a construção das rodovias; em um segundo momento apontamos as transformações no eixo da rodovia BR-163 com as novas rotas de circulação de derivados de petróleo e de commodities agrícolas e a transformação do município de Itaituba em um importante nodal de circulação; por fim, abordamos a rodovia BR-319 em três momentos históricos da construção/trafegabilidade, interrupção do tráfego e o retorno dos fluxos, destacando ainda, a expansão dos investimentos empresariais no município de Humaitá com a construção de novos portos fluviais.

A realização da pesquisa que resultou neste artigo esteve pautada em duas partes, uma constituída pelas leituras de textos sobre transportes, logísticas e redes na Amazônia, e a outra, na realização das atividades de campo na BR-163 entre 23/02/2018 até 05/03/2018 e na BR-319 no período de: 26/12/2016-01/01/2017, 27/02/2017-01/03/2017, 16/01/2018-20/01/2018 e 18/07/2019-28/07/2019.

\section{Alteração na circulação regional com as rodovias na Amazônia}

A construção e melhoria das rodovias na Amazônia após 1968 ocasionou um processo de complexidade da configuração regional, antes centrado majoritariamente na navegação fluvial e com pouca expressividade do transporte aéreo, passando a ter um conjunto de sistemas de engenharia de grandes extensões que foram materializados dentro de uma perspectiva clássica da geopolítica centrada na integração e coesão territorial, 
tendo ainda como propósito, o aumento da densidade demográfica e a expansão de atividades econômicas.

Com a abertura de novas rodovias, altera-se a rede urbana de parte da região Amazônica, pois, nem toda a região passou a ser dotada desse sistema de engenharia, que segundo Ribeiro, a inserção das rodovias representou uma "ruptura do tradicional padrão espacial dendrítico, com a localização dos centros em "terra firme" (rodovia), em detrimento da "beira" (rio). Os núcleos urbanos assentam-se, agora, de acordo com a malha rodoviária programada pelo Estado" instituindo uma rede urbana com deslocamentos rodoviários "superando-se a rede urbana dendrítica preexistentes" (1997, p. 67) visualizados na figura 1.

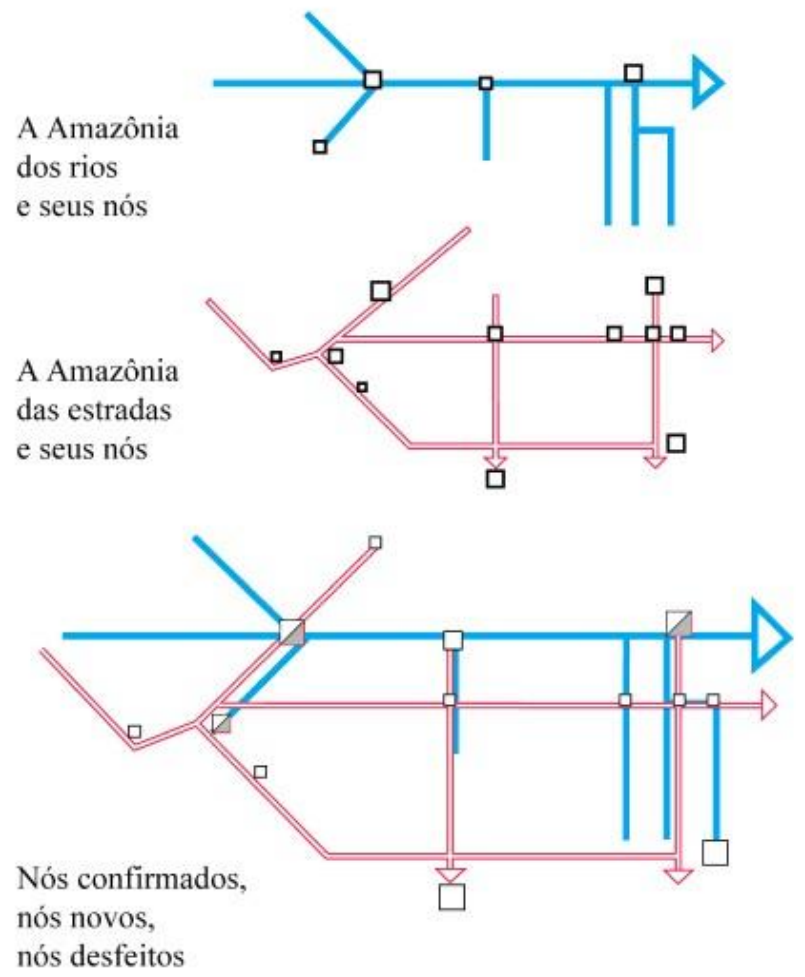

Figura 1. Rios e rodovias na Amazônia em um modelo (THERY, 2005, p. 39).

Os autores Almeida e Ribeiro (1989, p. 63), apontam que a construção das rodovias de grande extensão "alterou profundamente a estrutura espacial de transportes na região, passando de um sistema simples, baseado na navegação fluvial, para as etapas iniciais de um sistema complexo" que engloba o uso de todos os modais existentes.

Segundo Corrêa, as cidades que estavam ao longo dos eixos rodoviários "transformaram-se em importantes centros de serviços para as atividades e população de suas áreas de influência, bem como passaram a desempenhar o papel de centros de mãode-obra" (1987, p. 61). Nessa direção, tais transformações na rede urbana promoveu novas sociabilidades econômicas e sociais a parir da década de 1960 (CORRÊA, 1987).

Uma das principais alterações pontuadas por Corrêa constituiu do rompimento da existência de uma rede urbana dendrítica "com uma funcionalidade monotônica, a de drenagem de produtos do extrativismo vegetal e excedentes sob a forma de lucros comerciais e juros" tratava-se de uma rede de cidades com "novos significados derivados do fato dela ter sido alterada diretamente - através de modificações funcionais e na organização interna dos núcleos preexistentes e da criação de novos núcleos - pelo capital 
industrial e financeiro e pelo Estado capitalista" com a inserção de novas atividades econômicas e divisões do trabalho e de produção na Amazônia (1987, p. 65).

A construção das rodovias na Amazônia (quadro 1) esteve vinculada a premissas constituídas em integração territorial, povoamento da hileia amazônica e acesso as fronteiras. Para Ribeiro, o objetivo do governo "era o de atrair populações para a Amazônia e integrá-la ao restante do país, principalmente ao centro mais dinâmico - o Centro Sul" (1998, p. 74). Essa atração ocorreria com a política de colonização, grandes projetos de mineração, instalação de indústrias e demais obras/projetos. Além desse processo, houve o avanço do desflorestamento, deslocamento de conflitos para a nova frente pioneira e a inserção de problemas sociais com caboclos, ribeirinhos e indígenas (OLIVEIRA, 1988).

Quadro 1: rodovias federais construídas na Amazônia

\begin{tabular}{|c|c|c|c|c|c|}
\hline Rodovia & Trecho & Construção & Pavimentação & Condições & Distância km \\
\hline BR-174 & Manaus-Caracaraí & $1968-1977$ & 1998 & Trafegável & 975 \\
\hline BR-319 & Manaus-Porto Velho & $1968-1976$ & 1975 & $\begin{array}{l}\text { Parcialmente } \\
\text { trafegável e } \\
\text { com } \\
\text { trafegabilidad } \\
\text { e sazonal em } \\
450 \mathrm{~km}\end{array}$ & 877 \\
\hline $\begin{array}{l}\text { BR-010 } \\
\text { BR-153 }\end{array}$ & Belém-Brasília & $1959-1960$ & 1974 & Trafegável & 1970 \\
\hline BR-364 & Brasília-Acre & $1960-1961$ & $1984 / 1989$ & Trafegável & $2000 *$ \\
\hline BR-401 & $\begin{array}{l}\text { Boa Vista-Bonfim- } \\
\text { Normandia }\end{array}$ & $1970-1972$ & & Trafegável & 185 \\
\hline BR-163 & Santarém-Cuiabá & $1970-1976$ & 2020 & Trafegável & 1777 \\
\hline BR-307 & $\begin{array}{c}\text { Cucuí-São Gabriel da } \\
\text { Cachoeira }\end{array}$ & 1973-1989 & - & $\begin{array}{c}\text { Parcialmente } \\
\text { Trafegável }\end{array}$ & 202 \\
\hline BR-210 & Porto Grande-Mitú & 1973-1977 & - & $\begin{array}{l}\text { Trechos } \\
\text { trafegáveis e } \\
\text { com fluxos } \\
\text { sazonais }\end{array}$ & - \\
\hline BR-317 & Lábrea-Assis Brasil & 1970-19 & - & - & - \\
\hline BR-080 & $\begin{array}{l}\text { Brasília-Manaus-São } \\
\text { Gabriel da Cachoeira }\end{array}$ & - & - & - & - \\
\hline BR-425 & $\begin{array}{l}\text { Abunã-Guajará- } \\
\text { Mirim }\end{array}$ & 1975 & - & Trafegável & 120 \\
\hline BR-432 & Boa Vista-Normandia & $1970-1972$ & $\begin{array}{l}\text { Apenas } 120 \mathrm{~km} \\
\text { asfaltados }\end{array}$ & Trafegável & 217 \\
\hline BR-156 & $\begin{array}{l}\text { Laranjal do Jari- } \\
\text { Macapá-Oiapoque }\end{array}$ & - & $\begin{array}{c}\text { Em } \\
\text { pavimentação }\end{array}$ & Trafegável & 965 \\
\hline
\end{tabular}

Fonte: Dnit (2019); *trecho Cuiabá-Rio Branco.

Desse conjunto de rodovias federais na Amazônia, a pavimentação das rodovias Belém-Brasília em 1974 e da Cuiabá-Porto Velho em 1984, ocasionou em transformações substanciais ao longo desses respectivos percursos, que vão desde a formação e consolidação de cidades, aumento da produção agrícola, conflitos sociais e redução da cobertura florestal (OLIVEIRA, 1988). 
Outra rodovia concluída foi a BR-174 no trecho Manaus-Caracaraí com a pavimentação inaugurada em 23 de novembro de 1998, favorecendo a partir de então, o deslocamento de veículos acima de 23 toneladas de peso bruto total ${ }^{1}$ e viagens com intervalo de 10-12h ao invés de dias de viagem. A conclusão estreitou ainda mais a relação entre as duas capitais regionais de Manaus e Boa Vista ${ }^{2}$.

A conclusão das rodovias Belém-Brasília, Cuiabá-Porto Velho-Rio Branco e Manaus-Boa Vista-Pacaraima ocasionou a formação e consolidação de novas redes de circulação com a redução do tempo de viagem. Esses três eixos, após suas respectivas conclusões, resultaram numa alteração na circulação interna em frações territoriais distintas da Amazônia, que no ano de 2008 tinha a seguinte configuração (fig. 2).

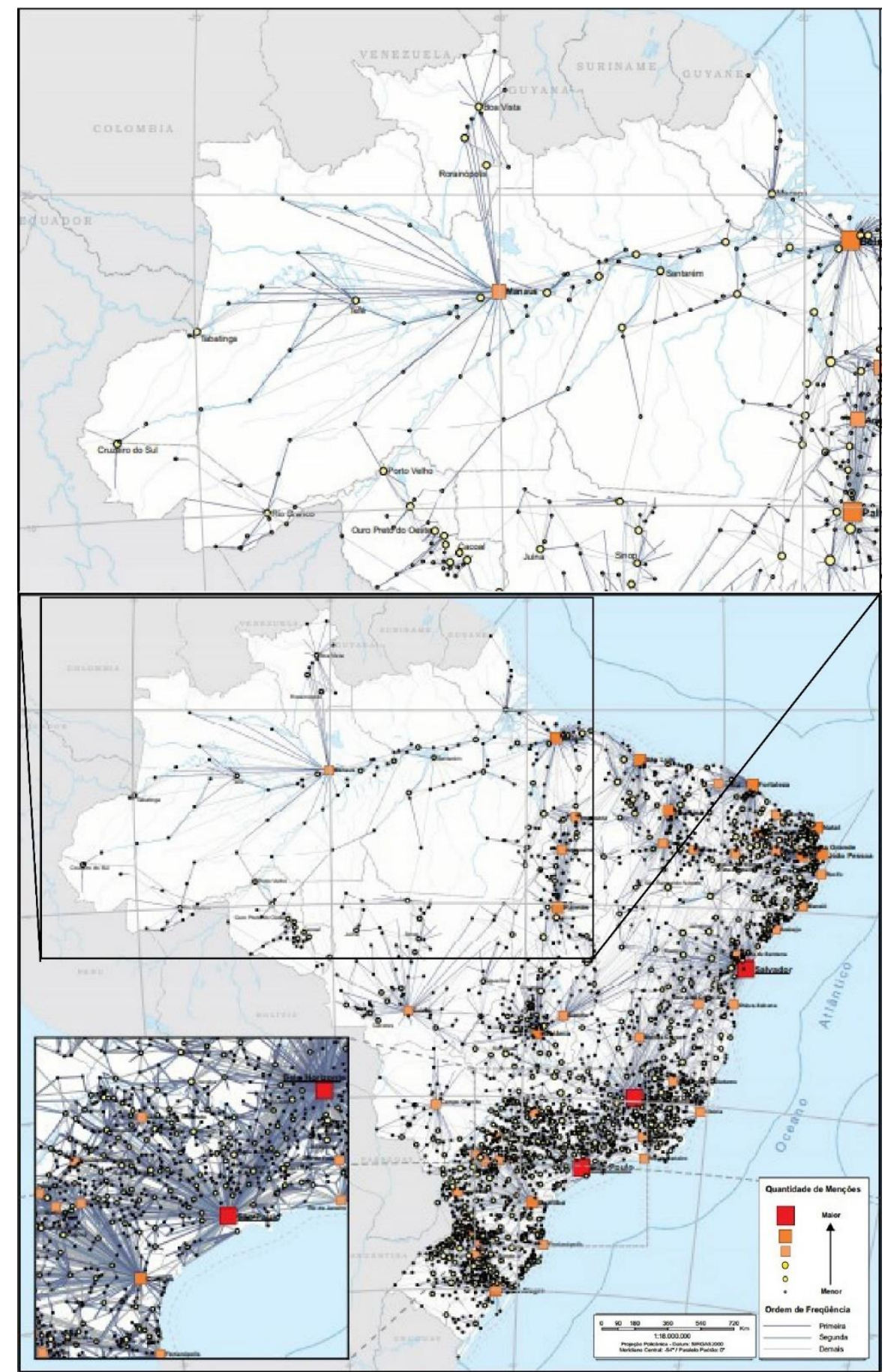

Figura 2. Destinos dos transportes coletivos no Brasil em 2007 (IBGE, 2008, p. 164). Org. autor. 
Nos últimos 10 anos (2010-2020), nota-se uma consolidação dos eixos de circulação, e para entender esse movimento, parte-se de uma análise da fluidez territorialmaterial para fins de compreender os fluxos de passageiros e de cargas "decorrente da reestruturação de alguns subsistemas de movimento" (HUERTAS, 2007, p. 1), com enfoque em identificar as transformações locais com a introdução de novos sistemas de engenharia, formação de novas redes e a existências de nós multimodais.

De acordo com Becker houve mudanças estruturais na Amazônia e novos processos na "fronteira", sendo um "espaço não plenamente estruturado e por isso mesmo capaz de gerar realidades novas. Dentre as mudanças, destaca-se a da conectividade regional, um dos elementos mais importantes na Amazônia" (2005, p. 73), sendo justamente essa conectividade via rodovias que se estruturam boa parte das "novas realidades" com a inserção de linhas de ônibus e do transporte de carga.

Para Arroyo, a fluidez territorial constitui na "qualidade dos territórios nacionais que permite uma aceleração cada vez maior dos fluxos que o estruturam" por meio da existência de sistemas de engenharia construídos e voltados "para garantir a realização do movimento" ao longo dos diferentes momentos do processo produtivo, seja na produção, distribuição ou consumo (2001, p. 105).

Conforme destaca Silva "a fluidez territorial é um imperativo necessário ao comércio internacional materializado no transporte bimodal - rodoviário e hidroviário sobre o controle dos atores hegemônicos" (2015, S/P) constituídos pelas tradings internacionais como Archer Daniels Midland-ADM, Bunge y Born, Cargill, Louis Dreyfus Company-LDC e as nacionais Caramuru e Amaggi.

Não se trata somente de uma expansão da frente pioneira marcada pela formação de vilas e expansão de atividades agrícolas, nos respectivos eixos, trata-se também da consolidação dessa expansão, claro que ainda tem o movimento de expansão da frente pioneira $^{3}$, mas atualmente nota-se a presença de investimentos que tange a um processo de incorporação de partes dessa região para outras atividades, como os transportes e os serviços atrelados a este, ou seja, esses investimentos da logística corporativa ocorrem numa área de frente pioneira que está em processo de consolidação.

Com a expansão e consolidação das frentes pioneiras, houveram diversos processos migratórios e um dos elementos técnicos que contribuíram para esse deslocamento foram os caminhões - pau de arara- e as linhas de ônibus que se estabeleceram durante o movimento "migratório em direção às terras que estavam sendo ocupadas [e] engendrou a formação de uma série de empresas de ônibus que passou a focar as crescentes demandas por transporte de passageiros" (HUERTAS, 2007, p. 128). Estas empresas desempenham um duplo papel, o primeiro no deslocamento de passageiros e "o papel de transportadora de encomendas" para as diversas cidades (HUERTAS, 2007, p. 193)

No período atual "criam-se condições para uma circulação mais densa, mais numerosa, mais extensa" (ARROYO, 2001, p. 141), e para tal, o Estado e as empresas atuam na consolidação de eixos de circulação e na montagem de novos sistemas de engenharia que são responsáveis por acelerar a circulação e de consolidar novos corredores de circulação.

No processo de criação de novas infraestruturas, principalmente por parte da logística corporativa, nota-se a formação de novos arranjos que são constituídos pelos nodais da rede rodoviária com intersecção com os rios Amazônicos. Esses nodais correspondem por frações territoriais distintas, mas que apresentam em seu bojo uma expressão máxima de seletividade espacial resultante das práticas espaciais realizada pelas empresas de transporte de carga e agroalimentares. "As práticas espaciais constituem ações espacialmente localizadas, engendradas por agentes sociais concretos, 
visando a objetivar seus projetos específicos" (CORRÊA, 2007, p. 68) e as ações desses agentes essencialmente corporativos são constituídas em práticas que podem ser identificadas como três principais apontadas por Corrêa (2007): seletividade espacial; fragmentação-remembramento espacial; antecipação espacial.

A seguir, os nodais pontuados nos tópicos dos eixos das rodovias BR-163 e BR319 correspondem em suas devidas proporções, a uma concentração de serviços, infraestrutura de circulação oriunda da logística do Estado e infraestruturas da logística corporativa ${ }^{4}$. Sendo que essa última atuou nos nodais tomando como base na seleção dos lugares que apresentavam as maiores vantagens para os investimentos, como a presença de rodovias asfaltadas ou em processo de conclusão, disponibilidade de área para montagem dos portos e acesso aos rios navegáveis ao longo do ano. Esses atributos associados a incorporação sistemática de investimentos em portos e demais infraestruturas de circulação criou um processo que Corrêa denominou de concentração espacial (2007, p. 69).

Os portos situados nos nodais das rodovias BR-163 e recentemente na BR-319 fazem parte também de um processo associados a fragmentação e remembramento espacial, constituídas em "criar unidades territoriais menores, passíveis de permitir operações mais rentáveis" (CORRÊA, 2007, p. 69). A rigor, os portos são unidades das empresas de transportes e de processamento que concentram suas filiais e plantas industriais no Centro-Oeste e destina parte das commodities para esses novos portos situados na Amazônia.

A expansão dos portos na Amazônia está por um lado relacionada a expansão da produção de grãos no Centro-Oeste e ao distanciamento dos tradicionais portos de Santos e Paranaguá (OLIVEIRA NETO, 2019), e por outro lado, está diretamente vinculada ao processo de modernização dos portos via aporte jurídico Lei n ${ }^{\circ} 8.630$ de 1993 que buscou "eliminar os obstáculos ao desenvolvimento do comércio exterior" e "aumentar a participação da iniciativa privada"(RODRIGUES, RODRIGUES, CASTRO, 2014, p. 119) com "a operação dos terminais [podendo ser] arrendada a empresa privada" (MONIÉ, 2019, p. 98) com potencialização desse processo com a Lei $n^{\circ} 12.815$, de 5 de junho de 2013 "Nova Lei dos Portos" que regulamentou "a exploração indireta do porto organizado e das instalações portuárias nele localizadas ocorrerá mediante concessão e arrendamento de bem público" (BRASIL, 2013).

Analisando o caso da rodovia BR-163, Margarit aponta que "a antecipação espacial adotada (...) não é uma iniciativa isolada, mas sim uma pratica ligada à competição intercapitalista entre empresas" (2013, p. 183). Além disso, "tais corredores, em muitos casos, são seletivamente escolhidos pelas corporações e não apresentam condições infraestruturais para essa função, como na expansão da frente pioneira para o Centro-Oeste, para o interior do Nordeste e para a Região Norte" (SILVEIRA, 2013, p. 44) como foi o caso particular da transformação da inconclusa BR-163 a partir de 2014 em um corredor de exportação.

Com o processo de melhorias e de pavimentação das rodovias Amazônicas nas últimas duas décadas, a atuação de empresas transportadoras e agroalimentares resultou numa potencialização dos fluxos microrregionais e regionais, sendo que tal intensificação é constituída em transformações ao longo dos eixos e em pontos nodais; estes passam a ser o lócus da fixação de capital excedente de outros lugares da própria Amazônia e do Brasil, como se estabeleceu nesses dez anos com a expansão da rede de postos de combustíveis na BR-163 e atuação das empresas de transporte de carga e de passageiros ao longo da BR-319. 


\section{BR-163: novos fluxos e novos sistemas de engenharia}

A proposta de interligar o Centro-Oeste até a cidade de Santarém data inicialmente de 1844 (ESTADO DE SÃO PAULO, 1976), pois desde aquele momento o caminho seria para fins de escoamento da produção agropecuária. No decorrer dos planos de viação do fim do século XIX e início do XX, os percursos entre Cuiabá e Santarém foram propostos como uma linha férrea e somente no início da década de 1970 o projeto tem início (fig. 3), mas sendo uma rodovia, pois permitiria acesso às terras para colonização e possibilitaria um investimento gradual.
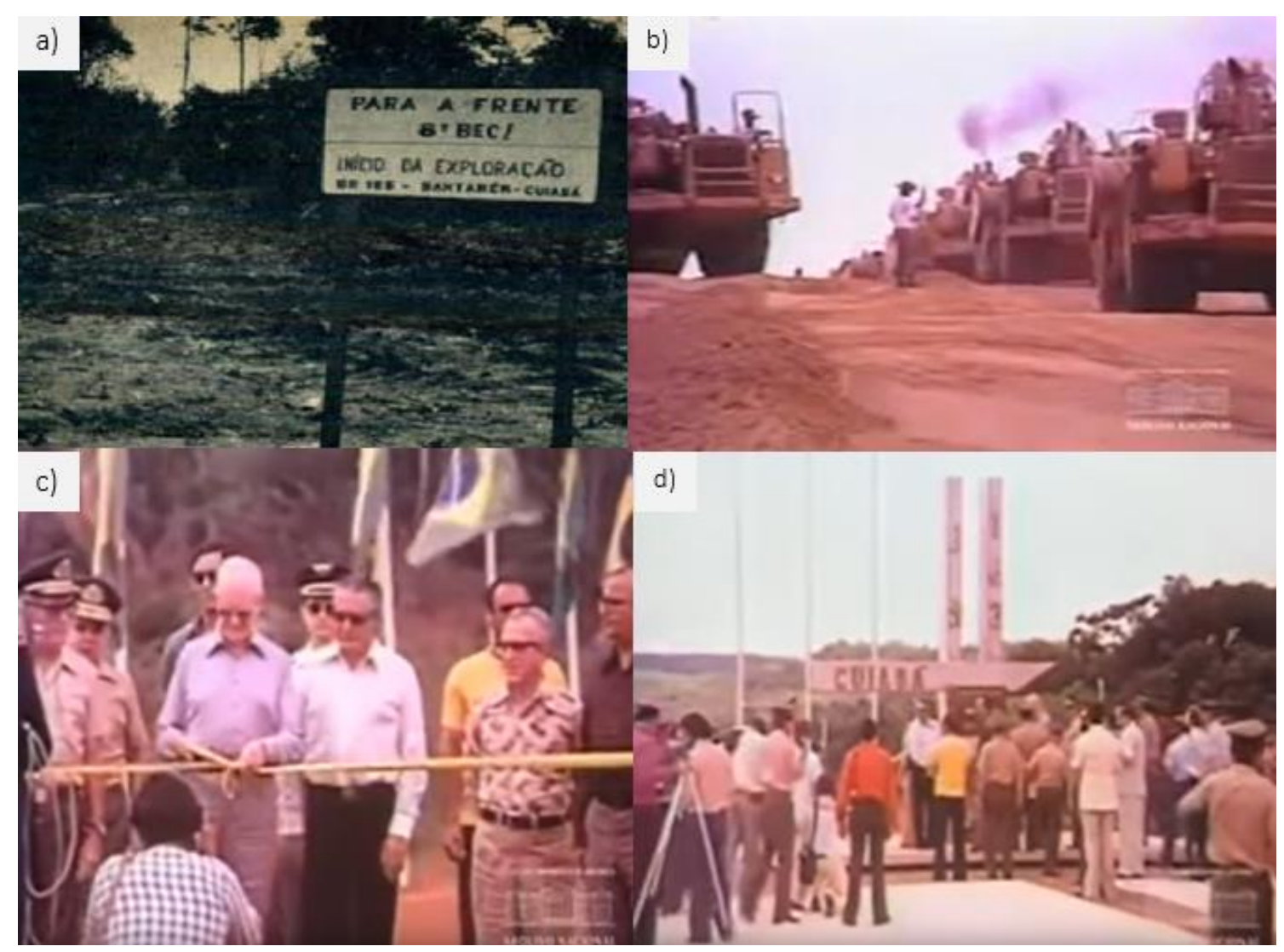

Figura 3. Construção da rodovia BR-163: a) início da construção da rodovia em outubro de 1970 (VEJA, 1970); b) moto scrapers na construção (BRASIL HOJE, 1976a); c) e d) inauguração da rodovia em 10 de outubro de 1976 (BRASIL HOJE, 1976b).

Entre o ano de 1976, quando foi inaugurada, até 1980, a rodovia não recebeu pavimentação asfáltica, somente entre 1981-1984 durante o Programa Integrado de Desenvolvimento do Noroeste do Brasil-Polonoroeste que um trecho de $330 \mathrm{~km}$ da BR163 entre o Posto Gil -entrada para Diamantino- e Sinop foi pavimentado e inaugurado em 1984 (MARGARIT, 2013, p. 20). Esse trecho concluído possibilitou a consolidação da expansão dos projetos agropecuários e de produção de grãos para o norte do estado do Mato Grosso.

Somente na década de 1990 que a pauta de melhorias da respectiva rodovia entra no cenário nacional (RENTE LEÃO, 2017) e, a partir de 2009, inicia-se a pavimentação da rodovia entre Guarantã do Norte (MT) e Santarém (PA) (MARGARIT, 2013). Vale apena apontar que a pavimentação da rodovia estava vinculada a um discurso de integração territorial e de propiciar acesso seguro aos portos no rio Amazonas para o 
escoamento das commodities agrícolas com a expansão da produção do Sul para o CentroOeste (MONIÉ, 2019; OLIVEIRA NETO, 2019).

Com o processo de pavimentação da BR-163 e a inauguração do primeiro porto graneleiro do tipo Estação de Transbordo de Carga-ETC no município de Itaituba em 2014, resultou em um redirecionamento regional dos deslocamentos antes centrados no porto graneleiro da Cargill em Santarém, passando a ter uma centralidade em Itaituba, com destaque para o distrito de Miritituba (fig. 4) que concentra 6 dos 7 ETC's existentes das seguintes empresas: Cargill, Hidrovias do Brasil, Bunge y Born, Cianport, Bertolini (flutuante) e RTL-Rio Tapajós Logística em construção, tendo ainda duas estruturas portuárias das empresas Equador e Atem para movimentação de derivados de petróleo, enquanto que na margem direita do rio Tapajós aproximadamente de $30 \mathrm{~km}$ da cidade de Itaituba está a ETC da Caramuru.

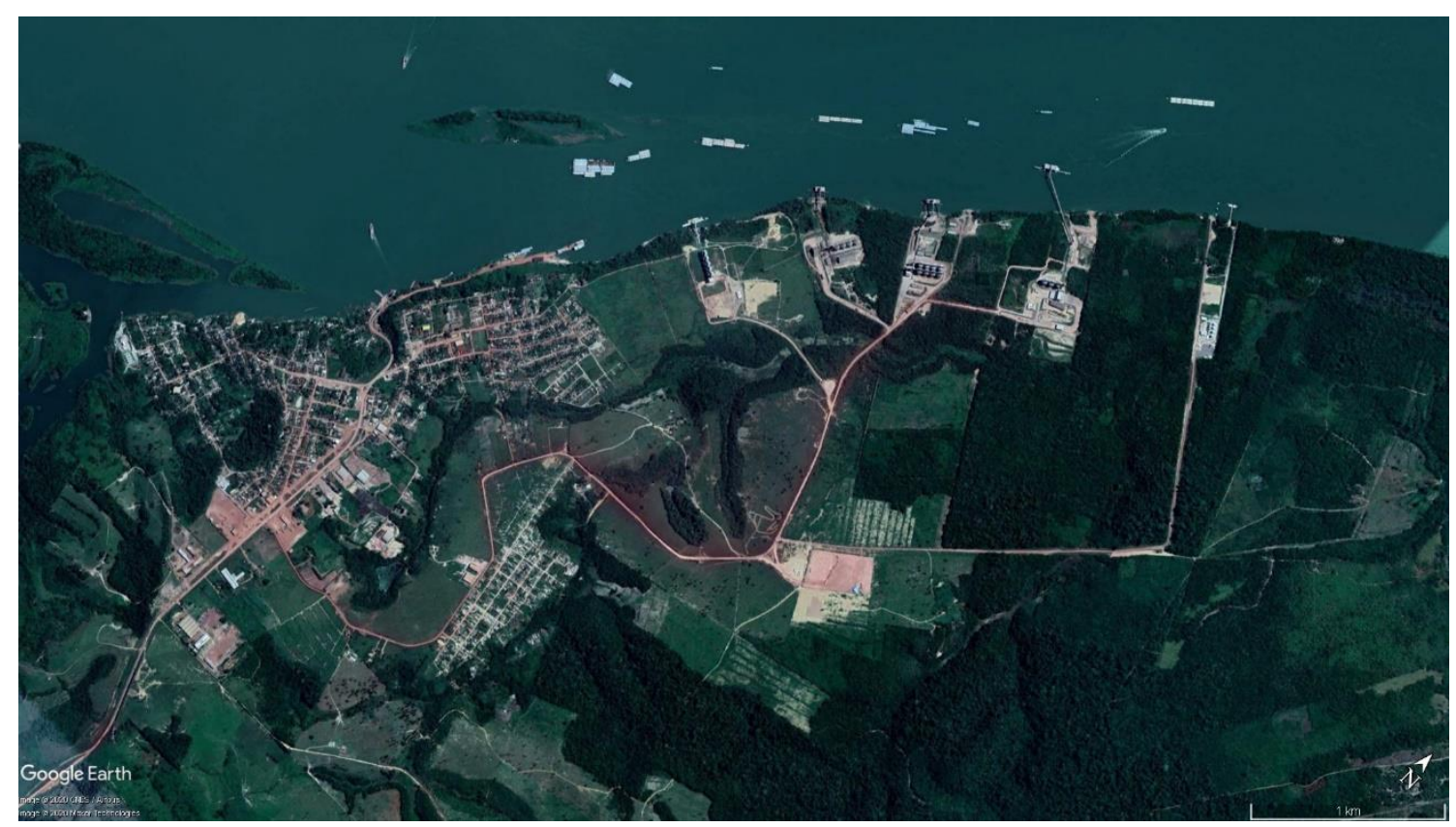

Figura 4. Portos no distrito de Miritituba/PA. Imagem de Google Earth Pro, imagem de 01/07/2018.

Vale ressaltar que o porto da Cargill em Santarém, inaugurado no ano de 2003, e os portos em Miritituba em funcionamento a partir de 2014, demonstram uma clara antecipação espacial ${ }^{6}$ por parte das empresas de logística e agroalimentares, pois, antes das condições ideais de trafegabilidade da rodovia BR-163 serem satisfeitas, os portos foram instalados.

Os elementos que o município de Itaituba possui e que compõem a seletividade espacial correspondem: a redução no percurso rodoviário em $300 \mathrm{~km}$ ao invés do percurso seguir para a cidade de Santarém via rodoviária; a disponibilidade de área para construção de portos e pátios de triagem/estacionamento; ao acesso ao rio Tapajós que é navegável para balsas e aos acesso a cidade com serviços e mão de obra.

A construção dos portos e demais infraestruturas (fig. 5) compõem um arranjo de objetos responsáveis pela fluidez oriunda de um redirecionamento dos fluxos antes centrados nos eixos Centro-Oeste-Porto Velho e Centro-Oeste/Santos/Paranaguá passando a ter fluxos para Itaituba. 

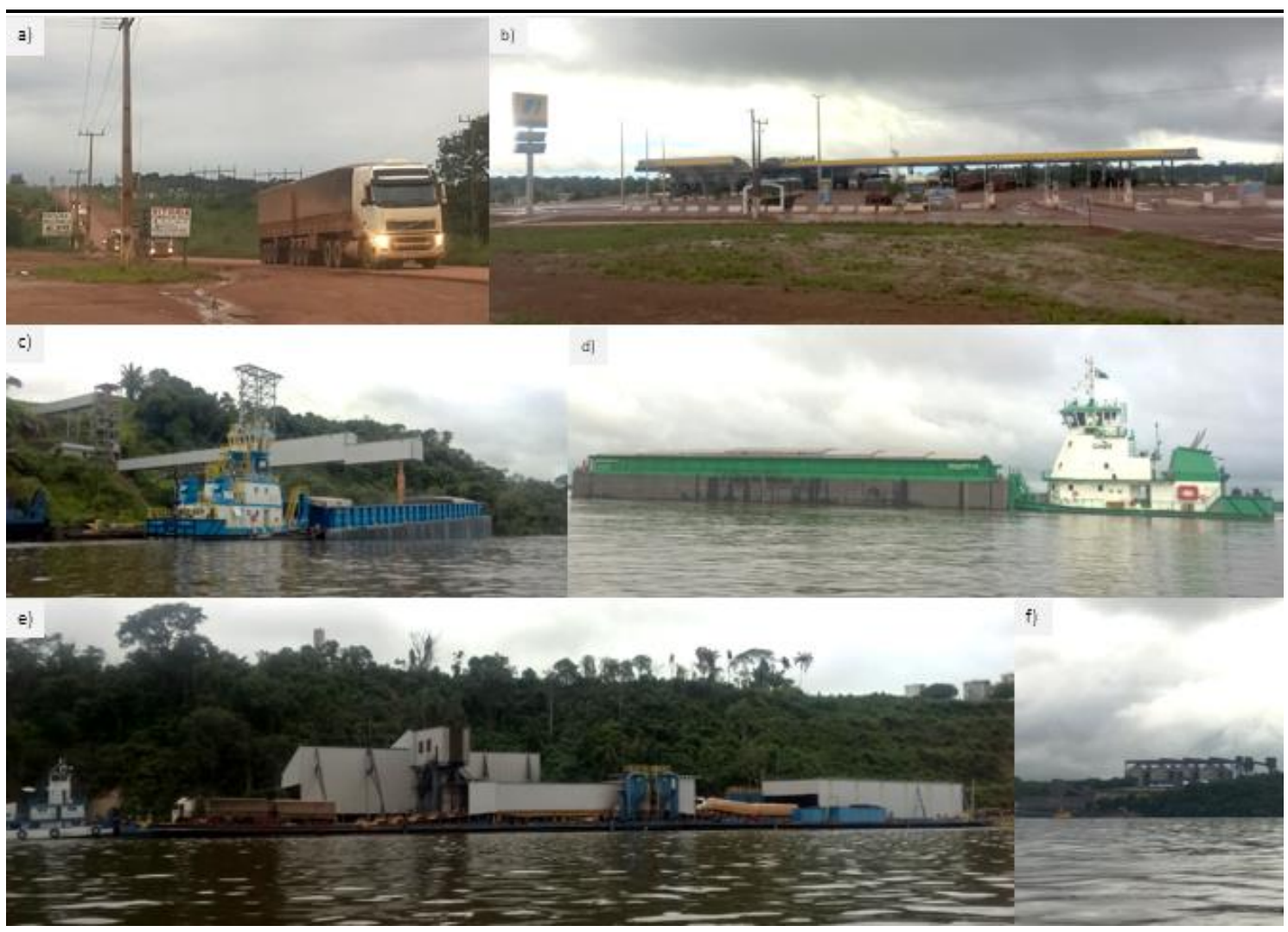

Figura 5. Fluxos e infraestruturas: a) carretas com grãos vindo do Mato Grosso; b) posto Miriam V; c) balsa no carregamento na ETC da Cianport; d) balsa da Cargill; e) ETC flutuante da Bertolini; f) ETC da Hidrovias do Brasil. Imagens do autor em 24/02/2018.

O nodal de Miritituba é essencialmente monofuncional com uma circulação de commodities agrícolas e outra composta pelos insumos, mas caso seja analisado na escala municipal, Itaituba como um todo apresenta um nodal da circulação de commodities, insumos agrícolas e derivados de petróleo, tendo previsões de transporte de contêineres e caminhões no sistema ro on caboclo $^{7}$, o que caracteriza como nodal polifuncional.

Huertas destaca que os nodais se estabelecem por meio das "interações espaciais que reforçam a interconectividade entre os agentes do transporte rodoviário de carga e destes com os agentes dos circuitos espaciais da produção" (2013, p. 10).

As infraestruturas do Estado e das corporações estão norteando a organização de parte dos fluxos no território tomando como base a respectiva necessidade de aumentar a fluidez para fins corporativos, a partir, de uma área com infraestruturas e serviços já existentes, notando-se a capacidade de condicionar novos processos vinculados para a existência de elementos pretéritos. De forma geral, "a logística de Estado e corporativa são destaques no reordenamento geoeconômico do território brasileiro" (SILVEIRA, 2019, p. 40).

Os nodais constituídos são frações territoriais com sistemas de engenharia de elevada carga técnica e com o propósito de oferecer serviços para o funcionamento dos fluxos entre as regiões produtoras até as áreas consumidoras, perpassando por parte do território nacional e da região Amazônica, com deslocamentos focados na eficácia do ato e nas operações.

Seguindo uma linha temporal entre 1976 até 2020, a rede de circulação constituída pelas rodovias BR-230 e BR-163 apresentavam as condições de tráfegos precárias, pois, apresentavam apenas revestimento primário e sem pavimento, e a partir da década de 80, os trechos da BR-163 são pavimentados. Com a atuação do Estado na conclusão de 
trechos rodoviários na Amazônia entre 2009-2020, a rede de circulação se consolida (fig. $6)$.

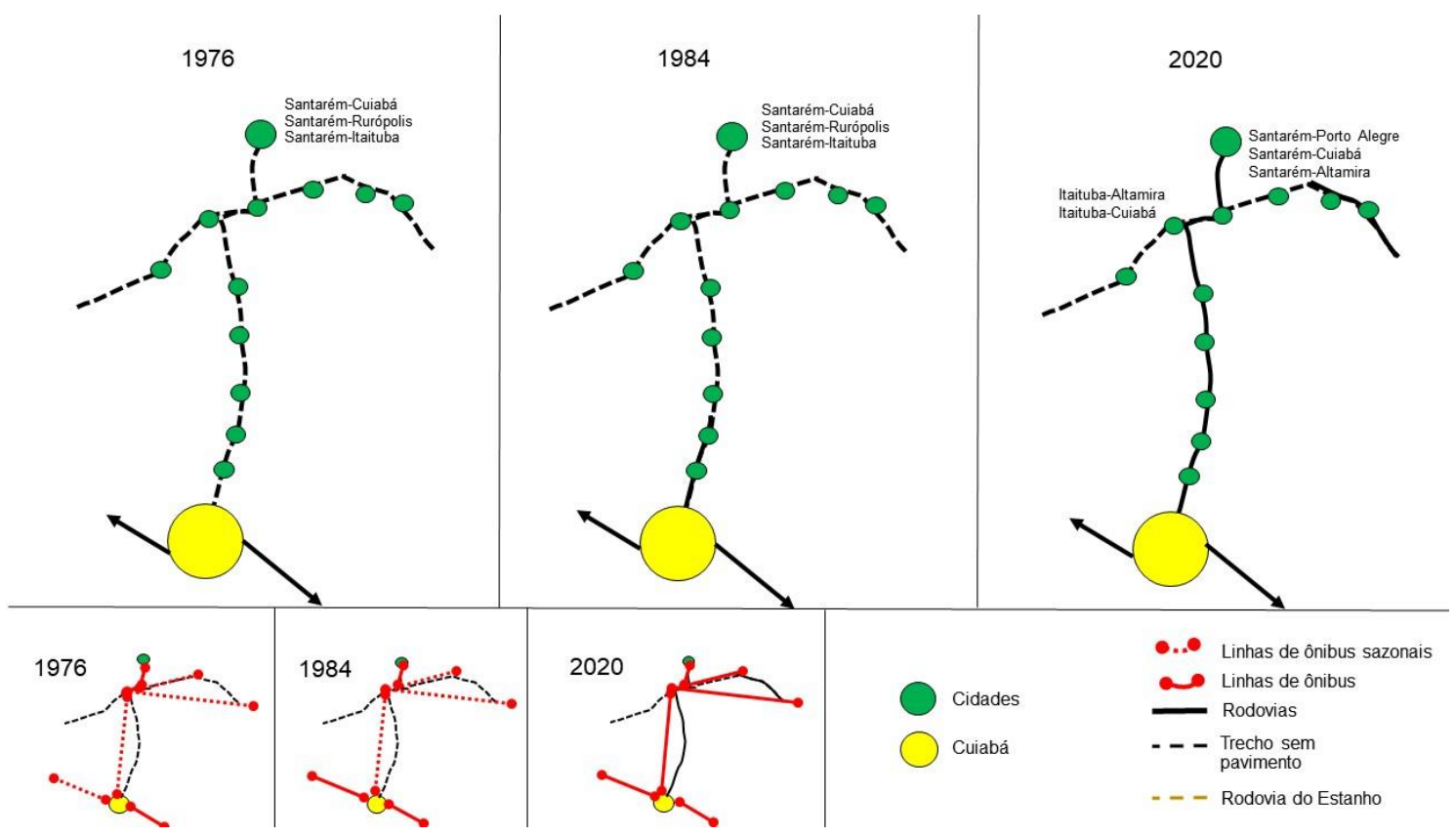

Figura 6. Modelo espacial das mudanças de fluxos. Org. autor.

A abertura das rodovias com o traçado em linhas, as interligações com outras rodovias e a sua continuação estando com deslocamento de mais de $30 \mathrm{~km}$ do ponto da primeira interligação, a travessia de rios em balsas, a instituição de vilas rurais -Agrovila, Agrópoles e Rurópolis- e o desenvolvimento de atividades como garimpagem, mineração industrial e construção de usinas hidrelétricas, foram elementos que colaboraram para a formação de aglomerações de casas e de pessoas. No caso particular da intersecção, entre as rodovias BR-230 e BR-163, teve a formação de dois importantes nós, um constituído primeiramente como cidade rural com a denominação de Rurópolis, inaugurada em 12 de fevereiro de 1974, distante $144 \mathrm{~km}$ de Miritituba e $112 \mathrm{~km}$ do entroncamento com a rodovia BR-163 que segue sentido Sul e a BR-230 que continua no sentido Oeste. Outro nó é constituído pelo distrito de Campo Verde (Trinta) estando no entroncamento das referidas rodovias e estando $30 \mathrm{~km}$ de Miritituba.

Nesse respectivo entroncamento houve a construção de um grande posto de combustíveis com pátio para 800 carretas. O posto, além de oferecer os serviços como abastecimento e lojas de conveniência, também abriga um dos pátios de triagem e de espera para os caminhoneiros, regulando o vai e vem dos veículos na entrada dos portos, evitando a formação de longas filas no descarregamento.

Com a dinâmica de circulação (fig. 7) de veículos na rodovia BR-163, tendo como ponto de passagem e de parada o município de Itaituba formando um nodal logístico que passou a ter a centralidade na rede de circulação com as infraestruturas portuárias, passagem dos ônibus rodoviários e serviços que passaram ou foram potencializados com os fluxos, que Santos identificou como eixo de maior número de passageiros ao longo da BR-163 "bem como a ligação com maior demanda e extensão mais longa (Porto Alegre/RS - Santarém/PA ${ }^{8}$, com 985.009 passageiros e 4.002 quilômetros)" (2019, p. 304).

No caso da BR-163 no estado do Pará, nota-se uma expansão nas atividades de transportadores rodoviário de passageiros com processo semelhante ao que ocorreu no 
eixo da BR-364 que "conforme a procura dos passageiros pelos serviços aumentava a frequência diária crescia, e com maior frequência horária e a melhoria nas condições de tráfego, a demanda aumentava, fechando assim um ciclo virtuoso" (SANTOS, 2019. p. 104).

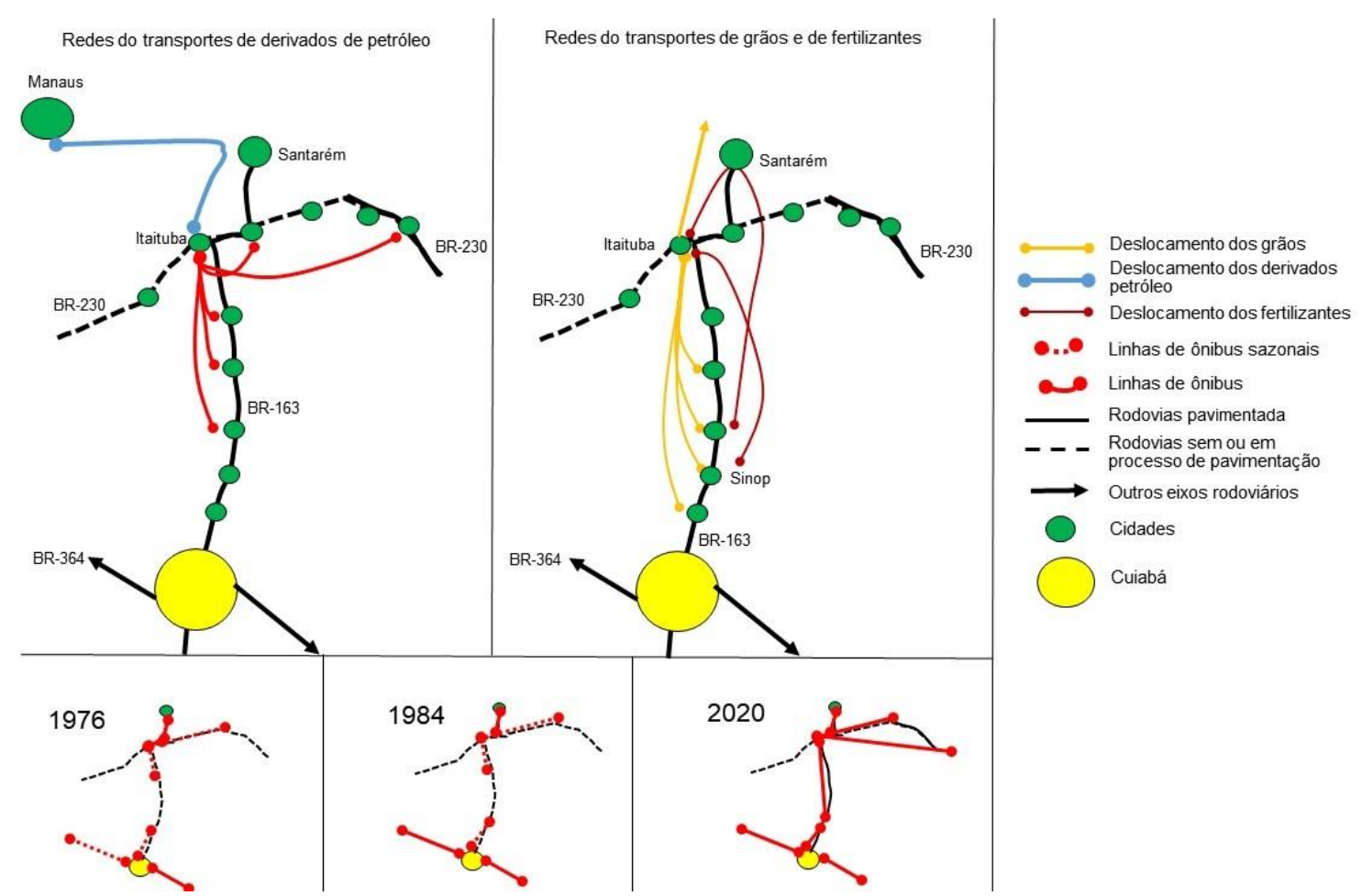

Figura 7. Fluxos dos transportes de derivados de petróleo, grãos e insumos agrícolas. Org. autor.

Dentre as infraestruturas que participam do conjunto logístico, destacamos os postos de combustíveis e os portos de recebimento e distribuição de derivados de petróleo, que são essenciais para o funcionamento do carregamento de commodities agrícolas e outros bens ao longo das rodovias.

A necessidade de ampliar a circulação altera o território "reconfigurado em novas territorialidades surgem como produto da mobilidade geográfica do capital abalizada nas demandas corporativas globais. O ordenamento do território é redirecionado para ampliar a fluidez territorial" (SILVEIRA, 2019, p. 45).

O nodal da rede engendra-se numa crescente complexidade funcional e articulada, a rigor, os sistemas de engenharia dispersos entre o distrito de Campo Verde e Miritituba constituem em uma fração do território com articulação essencialmente funcional com os fluxos de veículos transportando insumos agrícolas, grãos e derivados de combustíveis. Para Barros a "importância de Miritituba, como importante nó logístico do agronegócio de soja, responsável pela conexão do transporte de cargas de grãos pela estrada (rodoviário) - rio (hidroviário)" (2019, p. 395).

Conforme Raffestin (1993) argumenta, uma rede é inacabada e móvel, a sua respectiva configuração espacial e as suas mudanças históricas estabelecem um redesenho das dinâmicas pretéritas para as atuais nas redes e nos fluxos analisados. Nesse sentido, como apontamos anteriormente, as transformações ocorridas, seja pela melhoria nas condições de trafegabilidade ou pela inserção de novas e potencializadas dinâmicas econômicas, articulam os territórios estabelecendo hierarquias e desigualdades sociais e regionais.

A formação do nodal logístico é resultante da atuação da logística do Estado com a construção das rodovias e do porto da Companhias de Docas do Pará, com um acesso 
ao embarque e desembarque de cargas em Miritituba, tendo ainda o expressivo papel da logística corporativa com a montagem de sistemas de engenharia diversos como as ETC,s, pátio de triagem e postos de combustíveis que atuam ou assessoram a circulação rodoviária e o transbordo das cargas. Apesar desse processo de incorporação de frações territoriais e as dinâmicas econômicas nacionais e internacionais terem se estruturado no município de Itaituba e ao longo da BR-163 e de trechos da BR-230/PA, outras partes da Amazônia estão inseridas nesse processo, como é o caso do município de Humaitá no estado do Amazonas.

\section{BR-319: o retorno dos fluxos e os novos portos}

Durante o plano Operação Amazônia (1966-1970), deu-se início a construção de duas grandes rodovias na Amazônia, as rodovias BR-174 e BR-319, interligando a cidade de Manaus com Boa Vista e fronteira da Venezuela e a capital amazonense com a cidade de Porto Velho que já estava interligada precariamente com as cidades de Rio Branco, Cuiabá e Brasília.

A construção da rodovia entre as capitais regionais de Manaus e Porto Velho (fig. 8) teve início em junho de 1968 (UFAM, 2009; OLIVEIRA NETO, 2014), com duas frentes de serviços que se encontraram em 8 de novembro de 1972; a conclusão das obras e a respectiva inauguração ocorreram em caráter experimental em 27 de março de 1976 (FREIRE, 1985).

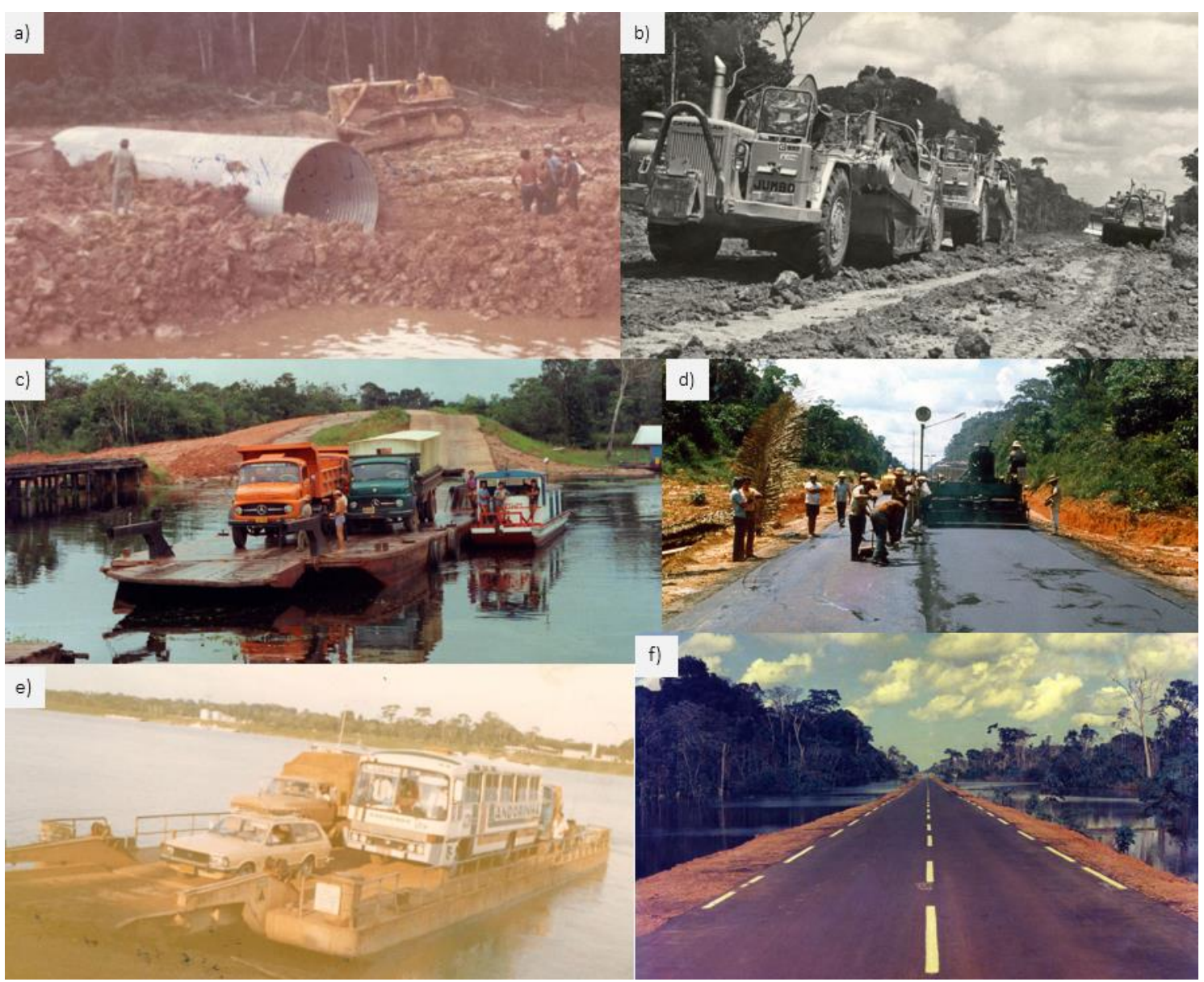

Figura 8. Construção da rodovia BR-319: a) colocação de bueiro metálico; b) moto scrapers nas obras de terraplanagem; c) travessia do rio Tupana; d) pavimentação asfáltica; e) balsa no rio Madeira com micro ônibus da empresa Andorinha da linha Porto Velho-Manaus; f) rodovia asfaltada. Fonte: Acervo Andrade Gutierrez, disponível em: <https://www.bancodeimagensag.com.br/> 
A rodovia BR-319 teve características distintas das demais rodovias, primeiramente, a sua justificativa é atribuída essencialmente à colonização de suas margens. Apesar do processo de ocupação ficar essencialmente centrado nas margens das rodovias e não se estendeu à configuração espacial de ramais, vicinais e travessões como na Transamazônica entre Marabá e Itaituba. Apesar da rodovia ter sido pavimentada completamente, sua trafegabilidade aconteceu de forma contínua entre 1976 até 1985, tendo um tráfego com paralizações sazonais até 1989, momento que houve o encerramento de linhas de ônibus, abandono de postos de combustíveis, fazendas e residências no trecho entre Humaitá até o Careiro Castanho (OLIVEIRA NETO, 2017).

Entre 1976 até 1989, nota-se uma alteração nas redes de transportes formadas ao longo dessa e de outras rodovias conectadas, pois, no período de trafegabilidade diversas empresas como Andorinha e Eucatur operavam o transporte rodoviário interestadual com rotas entre Manaus-Porto Velho, Manaus-Cuiabá e Cascavel-Manaus-Caracas ${ }^{9}$ (ALMEIDA, RIBEIRO, 1989) e o transporte intermunicipal operado pelas empresas Andorinha, Transamazônica, Marlin e Aruanã entre as cidades de Lábrea, Manicoré, Careiro Castanho, Humaitá e Apuí.

Com o período de encerramento das viagens a partir do final da década de 1980, essas linhas deixaram de ser operadas e o tráfego de veículos como caminhões e ônibus também ficou praticamente suspenso em decorrência das condições de trafegabilidade da rodovia, que apresentava trechos sem pavimento, queda de aterros e bueiros rompidos (FREIRE, 1985). Contudo, o transporte entre as duas capitais passou a ser realizado essencialmente pelos deslocamentos fluviais via rio Madeira em barcos regionais e ou balsas, sendo possível contar ainda com o transporte aéreo.

A circulação se manteve precária com passagem de poucos veículos, com destaque para: as equipes que realizam a manutenção nas torres de micro-ondas que estão situadas a cada $40 \mathrm{~km}$ e na rede de fibra óptica ao longo da rodovia; um fluxo entre o distrito de Realidade e a localidade de Piquia, com tráfego de um ônibus que transportava os moradores; uma movimentação de poucos veículos entre a comunidade do São Sebastião do Igapó Açú para a cidade do Castanho.

Nesse contexto, na figura 9 esboça-se um modelo da circulação ao longo da rodovia em três momentos históricos distintos, um entre o período de trafegabilidade, momento interrupção e o retorno da trafegabilidade sazonal ao longo da rodovia a partir de 2015 (A CRÍTICA, 2015).

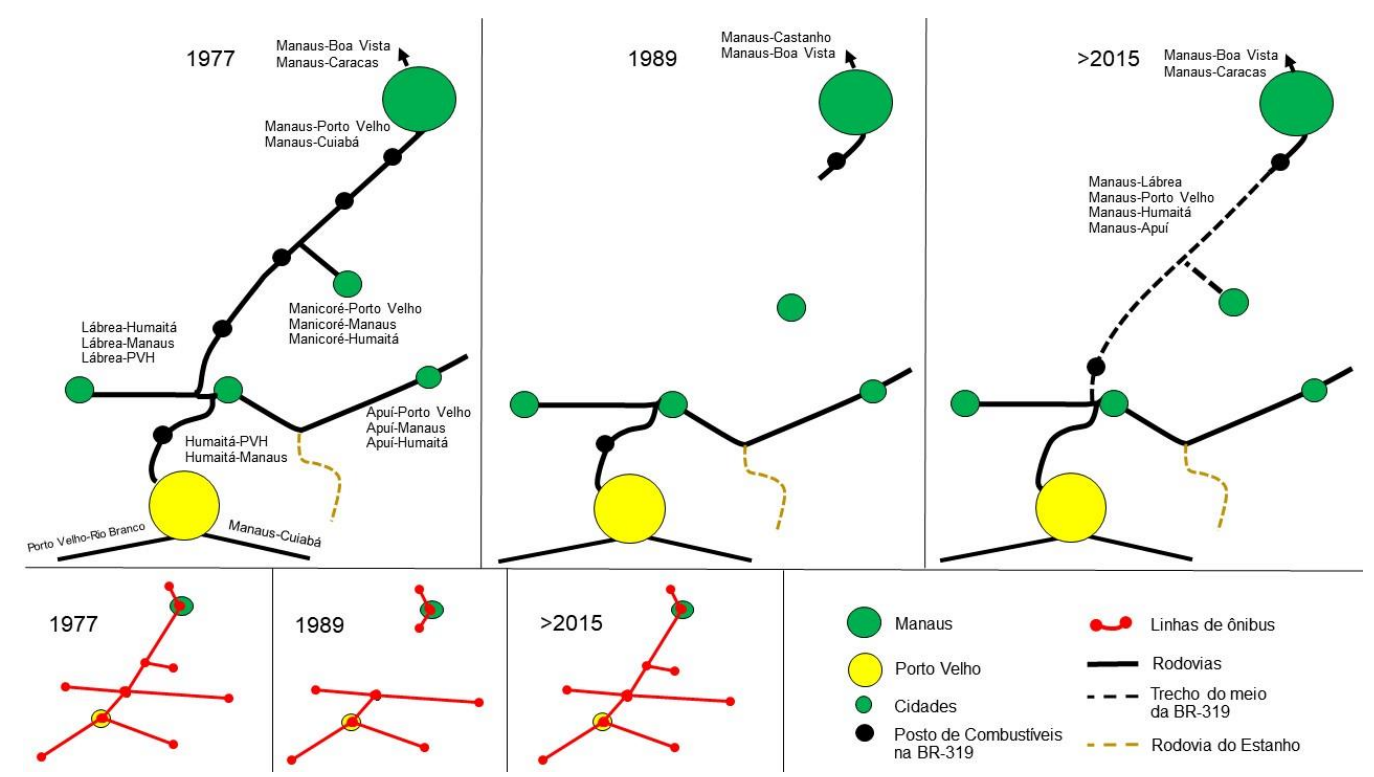

Figura 9. Três momentos da trafegabilidade da rodovia BR-319. Org. Autor. 
Os fluxos ao longo da rodovia BR-319 (fig. 10) atualmente estruturam-se em três grupos: transporte rodoviário de passageiros em ônibus com viagens entres as cidades de Manaus para: Manicoré, Humaitá, Apuí, Lábrea e Porto Velho; o segundo grupo é composto pelos carros de passeio que cruzam a rodovia entre as cidades, vilas e sítios; e o terceiro grupo é formado pelos caminhões e carretas que se aventuram transportar cargas ou retornar vazios pela rodovia.
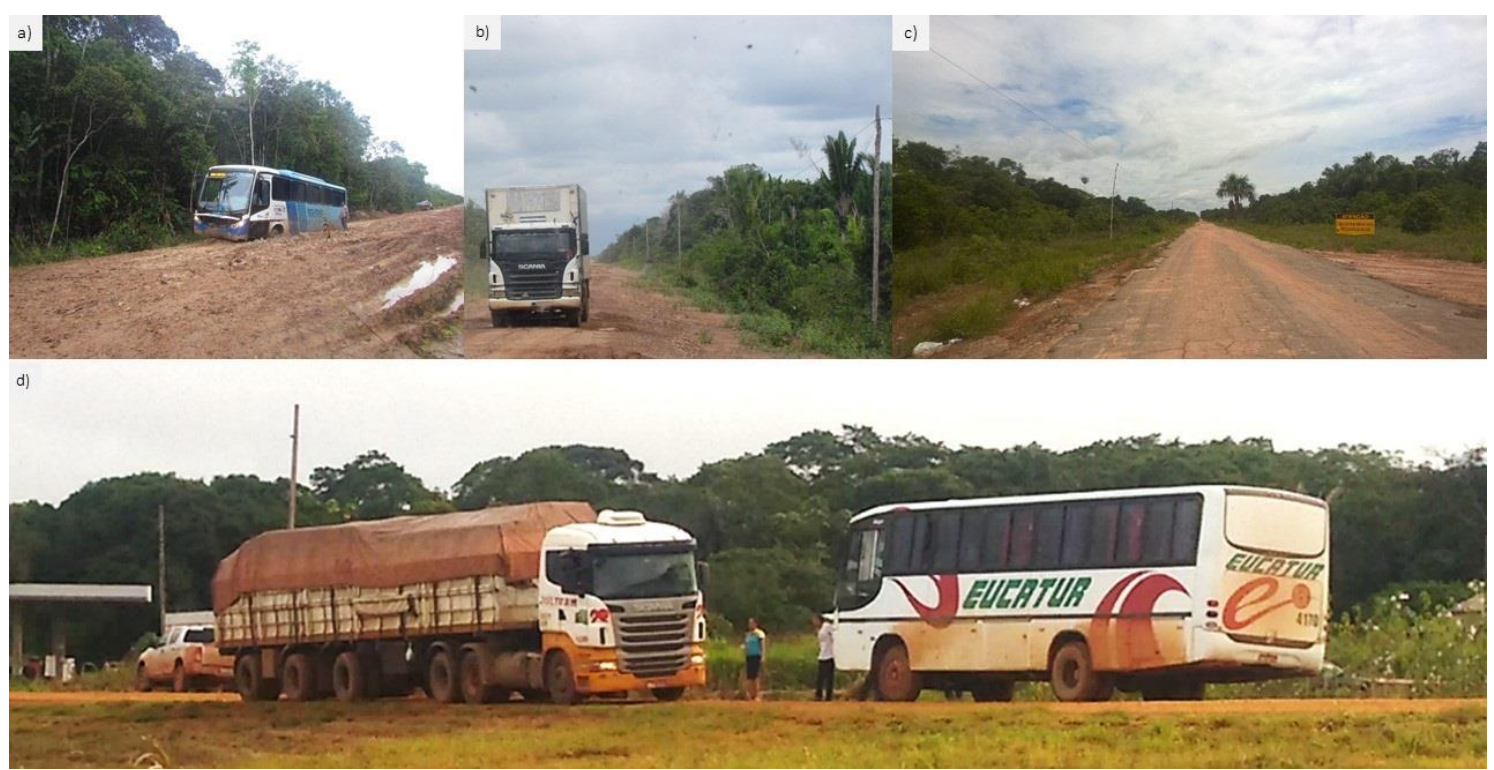

Figura 10. Rodovia BR-319: a) ônibus da linha Manaus-Porto Velho atolado no km 310; b) caminhão baú; c) BR-319 nas proximidades do entroncamento com a rodovia AM-366/BR-174B que permite a ligação com o município de Manicoré (imagens de 27/12/2016); d) carreta e ônibus circulando na rodovia no km 580 no distrito de Realidade (imagem de 16/01/2018).

Nesse contexto de reativação dos fluxos, deve-se se chamar atenção para a centralidade do nó da rede intermodal situado na cidade de Humaitá, que está ligada com Porto Velho em um trecho asfaltado da BR-319 e conectada com a BR-230 e tem acesso pelo rio Madeira, tendo nesse caso, dois elementos fundamentais para os transportes de carga; um ponto de entroncamento rodoviário e a possibilidade do transporte rodofluvial. Esses aspectos foram elementos fundamentais para atuação da logística corporativa no município, que primeiramente passou a ter um porto para o embarque e recebimento de balsas com caminhões, contêineres e demais cargas pertencentes a empresa J. F. de Oliveira Navegação "Chibatão", e o início das operações da ETC Ciagram ${ }^{10}$ da empresa Masutti no ano de 2018, com a movimentação de grãos oriundos do Mato Grosso. Esses dois casos denotam uma seletividade espacial dessas empresas, complementando o sistema logístico local e aumentando a circulação rodoviária para esse nó da rede. Isso demonstra uma clara manifestação de pratica de atores da logística corporativa no território.

Os portos que estão na cidade de Humaitá fazem parte de três circuitos distintos de transportes. O primeiro deles é o circuito do transporte regional com viagens e atracamento de embarcações com passageiros oriundos de cidades como Manaus, Porto Velho, Manicoré, Novo Aripuanã etc., balsa que realiza a travessia do rio Madeira com os veículos que vão seguir pela rodovia BR-230 com destino as cidades de Santo Antônio do Matupi, Apuí, Jacareacanga e Itaituba, e no sentido Humaitá, Lábrea, Manaus e Porto Velho. Ainda tem as embarcações da dinâmica local com características de porte reduzido, possuindo potência de 5 hp até $200 \mathrm{hp}$. 
O segundo arranjo é constituído pelas redes do transporte em balsas do modelo ro on caboclo que constitui no transporte de caminhões e semirreboques com ou sem o cavalo mecânico em cima da balsa, tendo ainda o transporte de contêineres e demais veículos. Nesse circuito, os principais pontos de circulação e de carregamento/descarregamento são nas cidades de Manaus e Porto velho ${ }^{11}$ e com a construção do porto da J. F. Transportes na cidade de Humaitá, a cidade amazonense passa a fazer desse circuito logístico da Zona Franca de Manaus.

O terceiro circuito é constituído pelo porto Masutti (fig. 11) com o transbordo da carga dos caminhões, armazenamento em silos e posterior carregamento em balsas graneleiras. Se por um lado, esse porto é uma alternativa aos portos situados no município de Porto Velho, por outro lado, acaba sendo um acesso para o escoamento da produção de grãos, principalmente de soja no município de Humaitá.

Abordando sobre a expansão da soja no Sul da Amazônia, Silva aponta que houve uma transformação mesma que de forma fragmentada em um "espaço da globalização das grandes empresas do agronegócio (tradings), cujos agentes hegemônicos territorializaram seus projetos econômicos com apoio dos governos e elites regionais, metamorfoseando o espaço num território corporativo do capital" que conseguiu alterar a composição técnica do território com a fluidez territorial e que se tornou em um dos atributos relevantes para a expansão (2015, S/P) dos sistemas de engenharia na Amazônia.

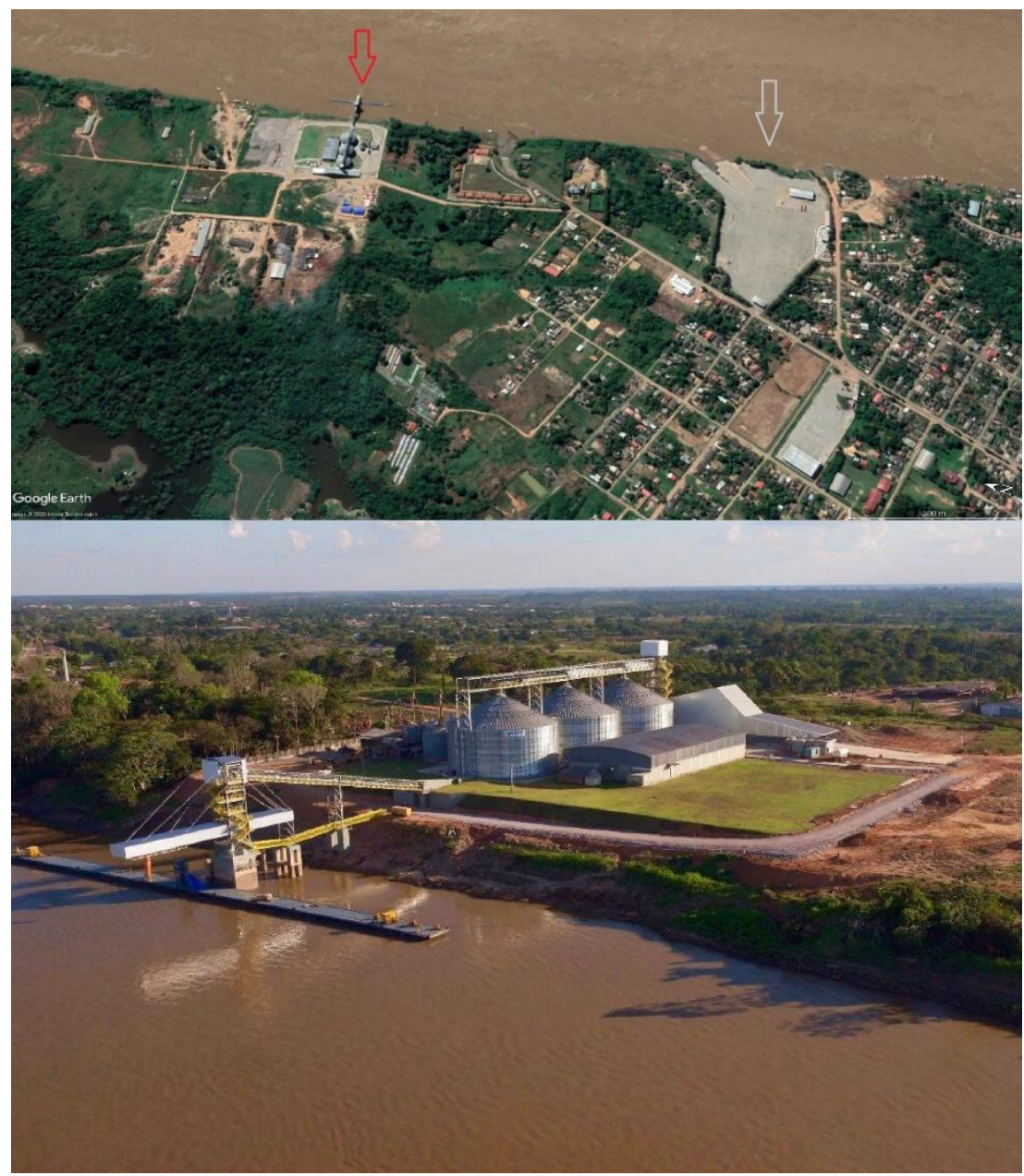

Figura 11. Portos na cidade de Humaitá/Am. Em seta vermelha porto graneleiro e em seta cinza o porto de cargas do Chibatão. Imagem de Google Earth Pro, imagem de 05/01/2020. ETC da Musutti na cidade de Humaitá. Fonte: Fockink (2018). 
O nodal de Humaitá potencializa ainda mais a centralidade de diversos fluxos no circuito logístico corporativo exógeno às dinâmicas do município que podem ser caracterizadas como nodal bifuncional, pois, nota-se infraestruturas e circulação de cargas do circuito espacial da produção de commodities agrícolas e um circuito espacial de bens da Zona Franca e do comércio da cidade de Manaus. A rigor, cada fluxo possui rotas diferentes (fig. 12).

De forma geral, as cidades passam a ter infraestruturas que "funcionam para assegurar a cadeia produtiva da soja e do gado, criando condições infraestruturais e superestruturais (...) [e as cidades] servem como nó logístico de uma rede de transportes nacional e internacional de escoamento de grãos e carnes" (SILVEIRA, 2019, p. 43).

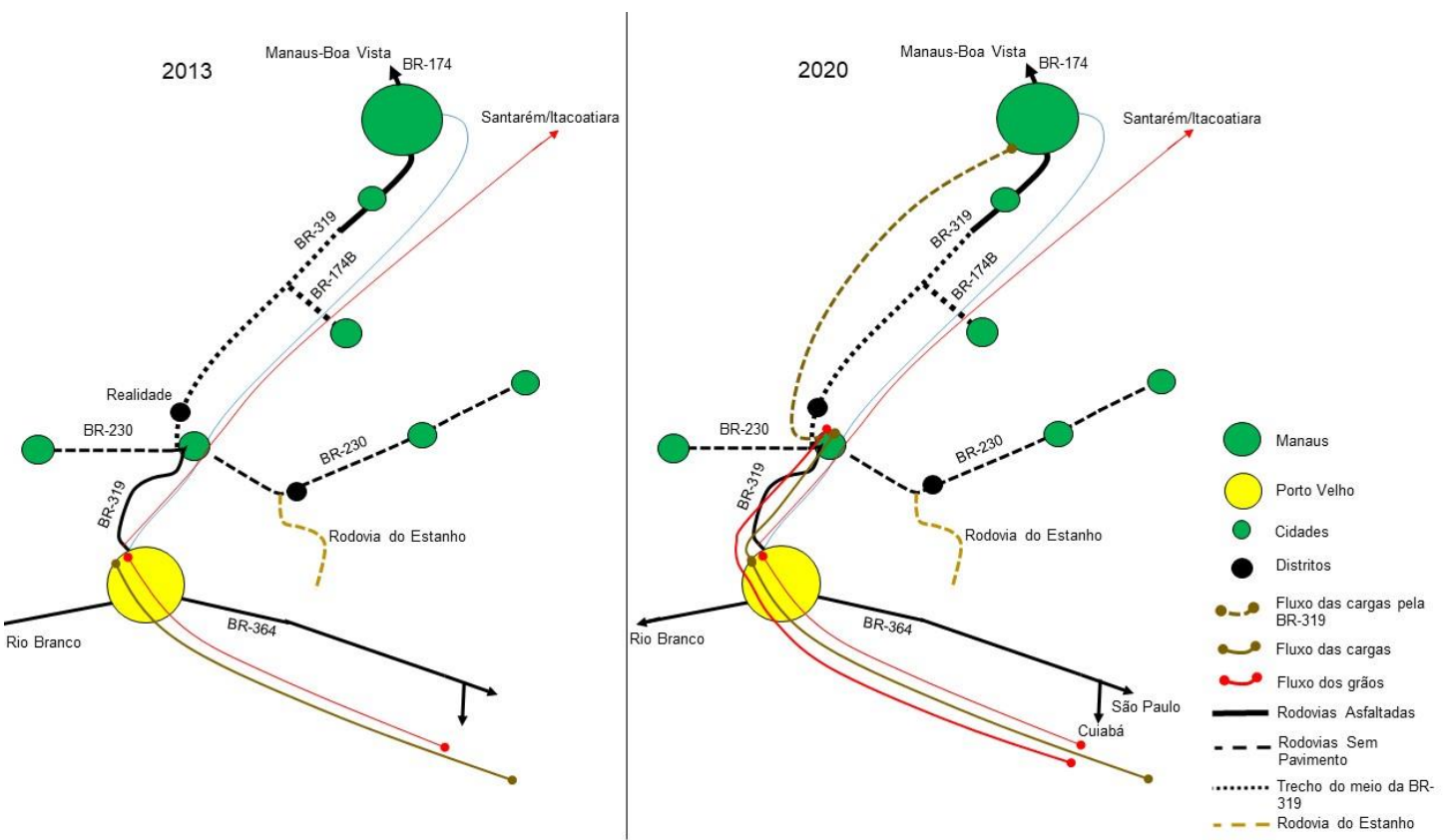

Figura 12. Modelo comparando os fluxos entre 2013 e 2020 com o retorno sazonal dos fluxos ao longo da BR-319 e com os portos. Org. Autor.

Esse contexto de pavimentação da BR-163 e de trechos da BR-230 no estado do Pará e o retorno da trafegabilidade sazonal na rodovia BR-319 no estado do Amazonas, ocasiona uma alteração nos fluxos e concomitantemente na espacialidade desta em determinadas frações territoriais da Amazônia. Nesse sentido, a rede urbana estabelecida pelo REGIC em 2008 (ver imagem 2) demonstra algumas ligações representadas, tomando como base um conjunto de variáveis, sendo que os dois eixos rodoviários passam a possuir uma dinâmica de fluxos que insere novas ligações antes não presentes na publicação de 2008 (fig. 13). 


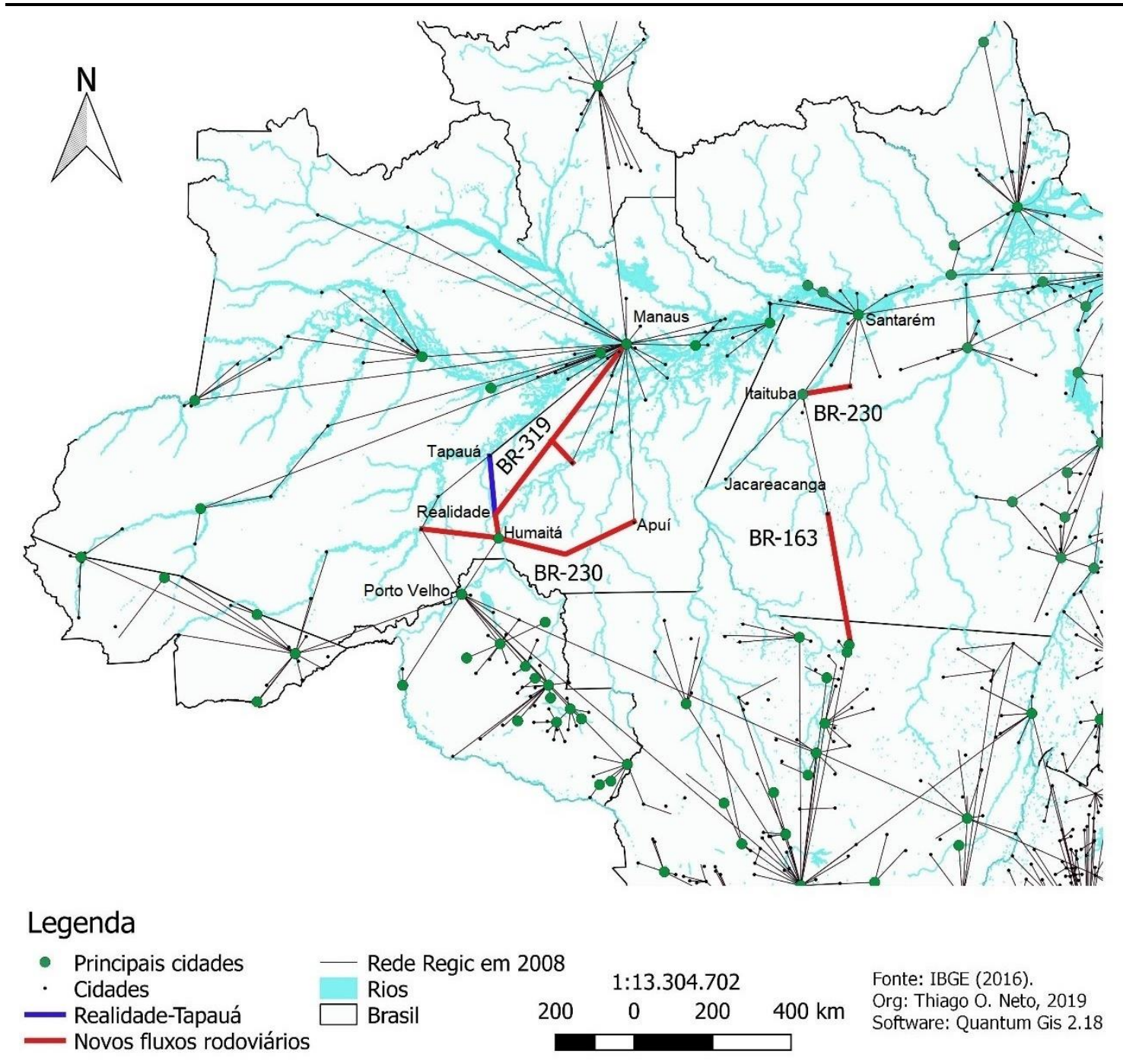

Figura 13. Mudanças nos fluxos terrestres com a inserção da BR-319 e BR-163. Org. Autor. Fonte dos dados: IBGE disponível em: <ftp://geoftp.ibge.gov.br/organizacao_do_territorio/divisao_regional/regioes_de_influencia_das_cidades/ Regioes_de influencia_das_cidades_2007/shapes/>

No caso da BR-319, as ligações sazonais ${ }^{12}$ realizadas pelas viagens rodoviárias em ônibus entre Manaus, Manicoré, Humaitá, Lábrea, Apuí e Porto Velho e as viagens fluviais da BR-319 no distrito de Realidade até o município de Tapauá constituem em um conjunto de novas linhas na representação da circulação e das redes entres as cidades. Enquanto com a pavimentação da BR-163 passa a incluir uma "linha" permanente de circulação entre a porção setentrional e meridional da Santarém-Cuiabá.

\section{Considerações finais}

O que se vivencia atualmente ao longo das rodovias BR-163 e BR-319, tomando as devidas particularidades de cada rodovia, é resultante de um processo duplo de integração e de incorporação de frações territoriais às dinâmicas econômicas e sociais, algo que se potencializou na Belém-Brasília, Cuiabá-Porto Velho-Rio Branco e ManausPacaraima quando esses respectivos caminhos foram asfaltados em décadas passadas.

As obras em fase final de conclusão da BR-163 no estado do Pará e nas melhorias na rodovia BR-319 entre Humaitá e Manaus, ocasionaram transformações espaciais nas 
redes de circulação ao longo desses dois eixos rodoviários resultando em transformações recentes nos fluxos das pessoas, produtos e serviços, com atuação das corporações na materialização de novos sistemas de engenharia, tendo ainda, a expansão e a consolidação do transporte rodoviário de passageiros entre as cidades conectadas.

Os novos papéis conferidos às cidades como Itaituba, em um nodal logístico com concentração de sistemas de engenharias vitais para os deslocamentos de commodities agrícolas e de derivados de petróleo, constituindo numa ação da logística corporativa. Outro nodal formado e que ganhou novos sistemas de engenharia foi a cidade de Humaitá, que está no entroncamento das rodovias BR-230 e BR-319, passando a ter um porto graneleiro e outro para o recebimento de cargas e caminhões em balsas. De forma geral, a logística de Estado e das corporações resultou no deslocamento de fluxos das commodities agrícolas para os portos amazônicos em uma clara tentativa de otimização das infraestruturas existentes, como forma de reduzir custos e a pressão nos eixos de circulação já consolidados das regiões do Sul e Sudeste.

Os novos sistemas de engenharia como os portos graneleiros construídos na Amazônia não fogem à regra de estarem situados nas proximidades de centros urbanos que oferecem redes de serviços como oficinas, postos de combustíveis, hotéis, bancos, mão de obra etc., o que implica positivamente para o funcionamento das atividades de transporte rodoviário, fluvial e de trasbordo das cargas.

Os novos portos estão instalados em diversas frações territoriais da Amazônia, de forma a coordenar redes de circulação dos comboios fluviais entre os portos fluviais até os portos de transbordo dos carregamentos fluviais em balsas para navios de percurso marítimo, além de instalar localmente com infraestruturas fixas ou flutuantes, instituir rotas de navegação e um conjunto de sistema de normas que são oriundos das empresas e estas visam manter as estruturas em funcionamento.

Os eixos rodoviários em processos de consolidação na Amazônia resultaram no aumento dos fluxos viários entre as cidades, distritos e vilas com uma potencialização de conflitos sociais resultante da expansão de atividades econômicas como é o caso particular das dinâmicas portuárias e de transporte no município de Itaituba, no Pará e da frente pioneira que se expande ao longo do trecho da rodovia BR-230 entre os municípios de Humaitá, Apuí e Jacareacanga com a expansão de atividades agrícolas e agropecuária.

A conclusão e melhoria na trafegabilidade das rodovias resultou em alterações na circulação regional com o adensamento de fluxos, redução do tempo de viagem, aumento no fluxo de veículos e a inserção de serviços e de um conjunto de sistemas de engenharias para atender as dinâmicas de circulação associadas as demandas econômicas nacionais e internacionais.

\section{Notas}

1 - Destaca-se o fluxo de caminhões e de carretas do tipo bitrens e rodotrens realizando o transporte de cargas para as cidades e o deslocamento da produção agrícola e agropecuária.

2 - "Os vínculos de Boa Vista efetivam-se com Manaus, com maior intensidade, a partir da implantação da rodovia BR-174, interconectado a metrópole amazonense, com a capital de Roraima. A rodovia BR-174 estreitou as relações de Boa Vista, principalmente com aquelas cidades situadas na porção setentrional do Estado" (RIBEIRO, 1998, p. 310).

3 - Ver definição em Monbeig (1984).

4 - Para Silveira a construção de infraestruturas, normatizações e agencias por parte do Estado constituem em uma "logística de Estado", enquanto a ação das empresas na construção de pequenos sistemas de engenharias como portos, armazéns e a administração de infraestruturas compõem a "logística corporativa", ainda destaca que quando articuladas conseguiram inibir "um "apagão infraestrutural" nos transportes e, por conseguinte, na fluidez no território brasileiro" (2013, p. 45).

5 - Além desses portos de movimentação de grãos, no distrito tem dois portos para o descarregamento granel de combustíveis das balsas para tanques e posteriormente o carregamento em carretas tanques. 
6 - Corrêa define como: "localização de uma atividade em local antes que condições favoráveis tenham sido satisfeitas" (2007, p. 70).

7 - Denominação regional para o transporte de carretas em cima da balsa (NOGUEIRA, 1994).

8 - Linha de ônibus Porto Alegre-Santarém com prefixo: 10-0019-00 / 10-0019-31 operado pela empresa Ouro e Prata.

9 - "Um exemplo de empresas que atuam nesses grandes eixos da região é a Empresa de ônibus União Cascavel - EUCATUR, que possui a mais extensa linha de ônibus do mundo (7 $200 \mathrm{~km}$ ), ligando Cascavel, no Paraná, a Caracas, na Venezuela, cortando sete unidades do território brasileiro - Paraná, São Paulo, Mato Grosso do Sul, Mato Grosso, Rondônia, Amazonas e Roraima e utilizando as seguintes estradas federais: BRs-163, 364, 319 e 174. A ligação total foi inaugurada em julho de 1985, porém, a ligação Cascavel-Boa Vista é servida pela EUCATUR desde 1971 e já transportou, até 1985, mais de 1 milhão de colonos, a maioria absorvidos pelos Estados de Mato Grosso e Rondônia. A empresa possui 500 veículos que rodam $2400000 \mathrm{~km} /$ ano e uma oficina completa em Ji Paraná (RO) que inclusive fabricou um veículo especial para a Amazônia - o "minissaia", com suspensão mais alta e sem bagageiros, com dois compartimentos: um para passageiros e outro para cargas (ALMEIDA, RIBEIRO, 1989, p. 64).

10 - O porto tem capacidade de movimentar 2 milhões de toneladas de grãos por ano.

11 - No sentido do rio Amazonas tem a rota entre Belém e Manaus. Com a instalação da ZFM, houve a formação de duas principais rotas de transportes de cargas no modelo ro on caboclo, uma entre Manaus e Porto Velho com a interdição da BR-319 e outra entre Manaus e Belém, tendo uma terceira rota com os portos de Itaituba e Santarém.

12 - Em decorrência do trecho da BR-319 entre as cidades de Humaitá e Manaus de 670km ter 450km sem pavimento e com aproximadamente 50 pontes de madeira torna as viagens realizáveis apenas no período de junho até dezembro se estendo as vezes no mês de janeiro. As viagens entre as cidades de Humaitá e Lábrea ao longo da BR-230 tem interrupção quando as condições de tráfego se torna precárias no período de dezembro-junho.

\section{Referências}

A CRÍTICA. Após 21 anos, empresa volta a fazer transporte intermunicipal no Amazonas pela rodovia BR-319. (07/10/2015). Disponível em: $<$ https://www.acritica.com/channels/cotidiano/news/apos-21-anos-empresa-volta-a-fazertransporte-intermunicipal-no-amazonas-pela-rodovia-br-319> Acesso em: 19 de jun. de 2020. ALMEIDA, Roberto Schmidt; RIBEIRO, Miguel Angelo Campos. Os sistemas de transporte na região norte: evolução e reorganização das redes. Revista Brasileira de Geografia, v. 51, n 2, p. 33-98, 1989.

ARROYO, Monica. Território brasileiro e mercado externo. Uma leitura do Brasil na virada do século XX. 2001. 250f. Tese de doutorado em Geografia Humana. Universidade de São PauloUSP.

BARROS, Márcio Júnior Benassuly. De agrovila a nó logístico do agronegócio na Amazônia: o caso de Miritituba, Itaituba, Pará. Geosuul, Florianópolis, v. 34, n 71, p. 382-406, 2019.

BRASIL. Plano de desenvolvimento regional sustentável para Área de Influência da Rodovia BR163 Cuiabá-Santarém. Brasília: Casa Civil, 2006.

BRASIL HOJE. Brasil Hoje, $\mathrm{n}^{\circ}$ 176, 1976a. Arquivo Nacional. Disponível em: <https://www.zappiens.br/portal/VisualizarVideo.do?_InstanceIdentifier=0\&_EntityIdentifier $=\mathrm{c}$ giBq99EyMg1AlIQxY0rCNeasp16W8Bho418FAz5fJ0WTc.\&idRepositorio=0\&modelo=0>

Acesso em: 15 de jan. de 2020.

BRASIL HOJE. Brasil Hoje, $\mathrm{n}^{\circ}$ 163, 1976b. Arquivo Nacional. Disponível em: <https://www.zappiens.br/portal/VisualizarVideo.do?_InstanceIdentifier=0\&_EntityIdentifier=c giLinXAXnfcmXxePKxvZrjHLZgyxPwiZ2CD7ejDWw4mRM.\&idRepositorio=0\&modelo=0> Acesso em: 15 de jan. de 2020.

BRASIL. Lei $\mathrm{n}^{\mathrm{o}} 12.815$, de 5 de junho de 2013. Disponível em: < http://www.planalto.gov.br/ccivil_03/_Ato2011-2014/2013/Lei/L12815.htm> Acesso em: 20 de jan. de 2020.

BECKER, Bertha. Geopolítica da Amazônia. Estados Avançados, São Paulo, n 19, v. 50, p. 7186, 2005.

CORRÊA, R. L. A periodização da rede urbana da Amazônia. Revista Brasileira de Geografia, Rio de Janeiro, v. 4, n.3, p. 39-68, 1987. 
CORREA, Roberto Lobato. Diferenciação sócio-espacial, escalas e práticas espaciais. CIDADES, Presidente Prudente, v. 4, n. 6, p. 62-72, 2007.

ESTADO DE SÃO PAULO, São Paulo, 20/10/1976, Geisel inaugura hoje a Cuiabá-Santarém, p. 10

FREIRE. Maria Amélia Alcântara. A Política Rodoviária e a BR-319: Os custos de uma Decisão. 1985. 127f. Dissertação (Mestrado em Sociologia Política) - Programa de Pós-graduação de Ciências Sociais da Fundação Escolar de sociologia e Política de São Paulo, PUC.

HUERTAS, Daniel Monteiro. Da fachada atlântica ao âmago da hiléia: integração nacional e fluidez territorial no processo de expansão da fronteira agrícola. 2007. 315f. Dissertação de Mestrado em Geografia Humana, Universidade de São Paulo-USP.

HUERTAS, Daniel Monteiro. Território e Circulação: transporte rodoviário de carga no Brasil. 2013. 405f. Tese de doutorado em geografia humana, Universidade de São Paulo-USP.

IBGE. Região de influência das cidades. IBGE: Rio de Janeiro, 2008. Disponível em: <https://www.mma.gov.br/estruturas/PZEE/_arquivos/regic_28.pdf> Acesso em: 15 de já. De 2020.

MARGARIT, Eduardo. Os interesses em torno da pavimentação da BR-163: tramas políticas envolvidas na consolidação de um novo corredor logístico na Amazônia. Revista Mato-Grossense de Geografia, Cuiabá, nº 16, pp. 168-197, 2013.

MONBEIG, Pierre. Pioneiros e fazendeiros de São Paulo. São Paulo: Hucitec/Polis, 1984.

MONIÉ, Frédéric. Dinâmicas institucionais, operacionais e espaciais do processo de modernização do sistema portuário brasileiro. In: SILVEIRA, Márcio Rogério; FELIPE JUNIOR, Nelson Fernandes. Circulação, transportes e logística no Brasil. Florianópolis: Insular, 2019, pp. 95-121.

NOGUEIRA, Ricardo José Batista. Amazonas: Um estado ribeirinho / estudo do transporte fluvial de passageiros e de cargas. 1994. 151f. Dissertação de Mestrado em Geografia Humana, Universidade de São Paulo-USP.

OLIVEIRA, Ariovaldo Umbelino. Integrar para não entregar: Políticas Públicas na Amazônia. Campinas: Pairus, 1988.

OLIVEIRA NETO, Thiago. A geopolítica rodoviária na Amazônia: BR-319. Revista de Geopolítica, Natal, v. 5, n² 2, pp. 109-128, 2014.

OLIVEIRA NETO, Thiago. Relações capitalistas no Assentamento Realidade na BR-319, quilômetro 570 (Amazonas). Eutopía, Quito, n 12, pp. 123-138, 2017.

OLIVEIRA NETO, Thiago. Rodovia BR-163: Entre a geopolítica e a geoeconomia. 2019. $286 f$. Dissertação de Mestrado em Geografia. Universidade Federal do Amazonas-UFAM.

RENTE LEÃO, Andréa Simone. Na trilha da estrada: (des)caminhos do Plano BR-163 Sustentável como concepção para o desenvolvimento na Amazônia. 2017. 380f. Tese de doutorado em Ciências Sociais, Programa de Pós-Graduação em Ciências Sociais em Desenvolvimento, Agricultura e Sociedade. Universidade Federal Rural do Rio de JaneiroUFRRJ.

RIBEIRO, Miguel Angelo. Transformações na rede urbana: o exemplo da Amazônia. Boletim Goiano de Geografia, Goiânia, v. 17, n 1, pp. 63-72, 1997.

RIBEIRO, Miguel Angelo C. A complexidade da rede urbana amazônica: três dimensões de análise. 1998. 335f. Tese de doutorado em Geografia, Universidade Federal do Rio de JaneiroUFRJ.

RODRIGUES, Jondison Cardoso; RODRIGUES, Jovenildo Cardoso; CASTRO, Edna Maria Ramos. Transporte hidroviário, portos e terminais interiores na Amazônia Brasileira: uma análise sobre seus papeis na política pública territorial. Geo UERJ, N²5, pp. 115-137, 2014.

SANTOS, Bruno Candido dos. Divisão territorial do trabalho e transporte rodoviário interestadual de passageiros entre o interior sulista e a fronteira agrícola. 2019. 391f. Dissertação de Mestrado em Geografia Humana, Universidade de São Paulo-USP.

SANTOS, Milton. Metamorfose do espaço habitado, fundamentos. Teórico e metodológico da geografia. São Paulo: Hucitec, 1988.

SILVA, Gabriel Damasceno Bento da. Sistema de transportes e logística da soja na BR-163. In: III Simpósio Nacional de Geografia Agrária - II Simpósio Internacional de Geografia Agrária. 2005. Presidente Prudente. Disponível em: 
<http://www2.fct.unesp.br/nera/publicacoes/singa2005/Trabalhos/Artigos/Gabriel\%20Damasce no\%20Bento\%20da\%20Silva.pdf > Acesso em: 13 de jan. de 2020.

SILVA, Ricardo Gilson da Costa. Amazônia globalizada: da fronteira agrícola ao território do agronegócio - o exemplo de Rondônia. Confins, Paris, ${ }^{\circ}$ 23, S/P, 2015.

SILVEIRA, Márcio Rogério. Infraestruturas e logística de transportes no processo de integração econômica e territorial. Mercator, Fortaleza, n 12, pp. 41-53, 2013.

SILVEIRA, Márcio Rogério. Circulação, transportes e logística e seus impactos na fluidez e na competividade territorial no Brasil. In: SILVEIRA, Márcio Rogério; FELIPE JUNIOR, Nelson Fernandes. Circulação, transportes e logística no Brasil. Florianópolis: Insular, 2019, pp 17-65. THÉRY, Hervé. Situações da Amazônia no Brasil e no continente. Estudos Avançados, São Paulo, v. 19, n ${ }^{\circ}$ 53, pp. 37-49, 2005.

UFAM. Relatório de Impacto Ambiental - RIMA: Obras de reconstrução/pavimentação da rodovia BR-319/AM, no segmento entre os $\mathrm{km} 250$ e $\mathrm{km} \mathrm{655,7.} \mathrm{Caracterização} \mathrm{do}$ Empreendimento. Manaus: Universidade Federal do Amazonas-UFAM, 2009.

VEJA. N 110, 14 de outubro de 1970, p. 20. 